\title{
A culture-sensitive quantitative food frequency questionnaire used in an African population: 2. Relative validation by 7-day weighed records and biomarkers
}

\author{
UE Maclntyre ${ }^{1, *}$, CS Venter ${ }^{2}$ and HH Vorster ${ }^{2}$ \\ 'Department of Paediatrics and Child Health, PO Box 168, Medical University of Southern Africa, 0204 \\ South Africa: ${ }^{2}$ Department of Nutrition and Family Ecology, Potchefstroom University for Christian Higher \\ Education, Potchefstroom, South Africa
}

Submitted 15 November 1999: Accepted 14 February 2000

\begin{abstract}
Objective: To determine the relative validity of the culture-sensitive quantitative food frequency questionnaire (QFFQ) developed for the Transition, Health and Urbanisation in South Africa (THUSA) study by 7-day weighed food records, urinary nitrogen excretion and basal metabolic rate (BMR).

Design: A cross-sectional study.

Setting: A community-based study in a population stratified according to level of urbanization.

Subjects: Residents of the North West Province, South Africa, aged between 15 and 65 years. The weighed food record study comprised 74 participants while 104 participants collected 24-hour urine samples.

Methods: All participants were interviewed using the QFFQ. For the weighed food record study, participants kept detailed weighed food diaries for seven consecutive days. For the urinary nitrogen study, participants made one 24-hour urine collection. Completeness of the urine collections was checked against $240 \mathrm{mg}$ para-aminobenzoic acid. BMR was estimated by the Schofield equations.

Results: Spearman rank correlation coefficients between the QFFQ and weighed food record ranged between 0.14 (fibre) and 0.59 (vitamin C). The QFFQ tended to underestimate intakes compared with the weighed records. Quintile distributions were similar for both methods. The correlation between urinary nitrogen excretion and dietary intake was poor. Possible underreporting was identified for $43 \%$ of the participants with the QFFQ and 28\% with the weighed food record.

Conclusions: The QFFQ appeared to be a relatively valid instrument for the assessment of dietary intakes of the population of the North West Province. The use of biomarkers in this population was difficult and needs further investigation.
\end{abstract}

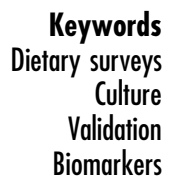

The 'nutrition transition" ${ }^{1}$ describes the changes in dietary patterns which occur when a population moves from a predominantly rural, traditional lifestyle to that of an urban, industrial one. Typically the traditional diet of African populations, high in unrefined carbohydrate and low in fat, takes on the characteristics of the so-called 'western diet' so that differences in dietary patterns among populations diminish ${ }^{2}$. The changes in dietary patterns, however, form part of the complex demographic, socioeconomic and epidemiological transitions which occur with urbanization. In an attempt to describe the nutrition transition within the wider context of the urbanization of the African population of the North West Province, South Africa, the Transition, Health and Urbanisation (THUSA) study was undertaken between 1996 and 1998. As there was no dietary assessment instrument appropriate for the study, a culture-sensitive quantitative food frequency questionnaire (QFFQ) was developed with the aim of describing both the food and nutrient intakes of the population.

The development of a dietary intake assessment instrument includes the testing of its reproducibility and relative validity in the target population. In the past, weighed food records have been used as the 'gold standard' against which other instruments have been measured $^{3}$. The weighed record, however, is itself subject to error ${ }^{3}$. This fact has led to the use of biomarkers, especially urinary nitrogen excretion and energy expenditure as independent markers of dietary intakes ${ }^{4}$. To date, no stringent procedures for the testing of relative validity have been applied to the development of dietary intake assessment instruments for use in African populations. The 
purpose of this study was, therefore, to determine the relative validity of the QFFQ developed for the THUSA study using a comparison with 7-day weighed food records and biomarkers (urinary nitrogen excretion and estimated basal metabolic rate).

\section{Subjects and methods}

Volunteers for both the 7-day weighed record $(n=85)$ and 24-hour urinary nitrogen studies $(n=104)$ were recruited from participants in the THUSA study $(n=890)$. All respondents gave written informed consent and were given a small payment on completion of the study. The study was approved by the Ethics Committee of the Potchefstroom University for Christian Higher Education.

\section{Seven-day weighed food record}

Respondents recorded their food and drink intake for seven consecutive days in a food diary. Detailed instructions and examples were given. Each day was divided into periods and columns were given for recording the time of consumption, the type, description and the weight or volume of food served and left over. Each respondent was given a scale with a capacity of $500 \mathrm{~g}$ and $5 \mathrm{~g}$ graduations (EKS, France), a measuring jug ( $500 \mathrm{ml}$ capacity, $25 \mathrm{ml}$ graduations) and a set of four measuring spoons (1, 2, 5 and $12.5 \mathrm{ml}$ ). Respondents were shown how to use the measuring equipment and to complete the food diaries. The diaries were checked on the second or third day of recording and at the end of the recording period.

Nutrient analyses were done by the FoodFinder program $^{5}$. Average energy, nutrient and food intakes obtained from the weighed records and the QFFQ were compared using Spearman rank correlation coefficients, $t$-test for paired differences, quintile distributions and Bland-Altman plots ${ }^{6}$.

\section{Twenty-four-bour urinary nitrogen}

Completeness of the 24-hour urine collections was checked by three $80 \mathrm{mg}$ para-aminobenzoic acid tablets (PABA; PABAcheck, Laboratories for Applied Biology, London) taken with meals on the day of urine collections. Specimens containing less than $85 \%$ (204 mg) PABA were considered incomplete ${ }^{7}$. Each respondent was given two 2-litre plastic bottles marked with the study number, in an opaque bag, a jug (female respondents), a safety pin to attach to his or her underwear as a reminder, the three PABA tablets, an instruction sheet and form to record the time of each urine output and any medications taken, problems experienced or specimens missed. Volunteers were instructed to collect urine the following day after discarding the first urine passed and including the first urine passed the next day. Respondents brought the urine collections to the research centre on the morning of the last collection. The volume of the 24-hour collection was recorded and four aliquots were stored at $-20^{\circ} \mathrm{C}$ before analysis.

PABA content of the urine specimens was analysed by chromatography, as described by Bingham and Cummings ${ }^{7}$. Nitrogen was determined by the Kjeldahl technique. The equivalent protein intake to nitrogen content of the urine sample was adjusted for skin and faecal losses using the formula:

$$
\text { Protein intake }\left(\mathrm{g} \mathrm{day}^{-1}\right)=6.25(\mathrm{UUN}+0.031 \mathrm{BW}) \text {, }
$$

where UUN is urine urea nitrogen $\left(\mathrm{gl}^{-1}\right)$ and BW is body weight $(\mathrm{kg})^{8}$.

Weights and heights of all respondents were measured using standard procedures. As there are no equations available for African populations, basal metabolic rate (BMR) was calculated according to the Schofield equations ${ }^{9}$. Ratios of energy intake (EI) to BMR of less than 1.2 were considered an indication of underreporting ${ }^{4}$.

Statistical analyses included the calculation of the means and standard deviations of the nitrogen and calculated protein excretion and Spearman rank correlation coefficients. The ratios of urinary nitrogen to dietary nitrogen (UN:NI) from both the QFFQ and the weighed record were calculated for each respondent.

\section{Results}

\section{Seven-day weighed food record}

Of the 85 volunteers recruited, 74 (87\%) returned usable weighed food records. The sample comprised 59 (80\%) females and 15 (20\%) males. The majority of volunteers (55\%) were from the middle-class urban stratum of urbanization while 11\%, 19\% and 15\% came from the rural, informal settlement and upper-class urban strata, respectively. Table 1 presents the Spearman rank correlation coefficients between the mean reported nutrient intakes of the weighed records and the reported intakes from the QFFQ. Although the correlation coefficients obtained for the sample were weak (0.1) to moderate (0.6), all except those of iron and vitamin A were statistically significant $(P<0.05)$.

The comparison of the mean intakes derived from the

Table 1 Spearman rank correlation coefficients $(R)$ between the 7day weighed record and quantitative food frequency questionnaire in an adult African sample $(n=74)$

\begin{tabular}{lcc}
\hline Variable & $R$ & $95 \% \mathrm{Cl}$ \\
\hline Energy & 0.31 & 0.09 to 0.50 \\
Protein & 0.30 & 0.07 to 0.49 \\
Carbohydrate & 0.31 & 0.08 to 0.50 \\
Fat & 0.25 & 0.02 to 0.45 \\
Fibre & 0.14 & 0.10 to 0.35 \\
Calcium & 0.24 & 0.01 to 0.44 \\
Iron & 0.20 & -0.03 to 0.41 \\
Vitamin A & 0.22 & -0.01 to 0.40 \\
Vitamin C & 0.60 & 0.43 to 0.73 \\
Alcohol & 0.53 & 0.34 to 0.68 \\
\hline
\end{tabular}


Table 2 Mean, standard deviation and differences between intakes of the 7-day weighed record (WR) and quantitative food frequency questionnaire (QFFQ) in an adult African sample $(n=74)$

\begin{tabular}{|c|c|c|c|c|c|}
\hline Variable & Method & Mean & SD & $\begin{array}{l}\text { Difference } \\
(\%)^{\star}\end{array}$ & $95 \% \mathrm{Cl}$ \\
\hline Energy (kJ) & $\begin{array}{l}\text { QFFQ } \\
\text { WR }\end{array}$ & $\begin{array}{l}8810 \\
9095\end{array}$ & $\begin{array}{l}3030 \\
2685\end{array}$ & 285 (3.2) & -488 to 1058 \\
\hline Protein (g) & $\begin{array}{c}\text { QFFQ } \\
\text { WR }\end{array}$ & $\begin{array}{l}67.4 \\
77.2\end{array}$ & $\begin{array}{l}22.0 \\
26.2\end{array}$ & $9.8(13.6)$ & 3.2 to 16.4 \\
\hline Carbohydrate (g) & $\begin{array}{c}\text { QFFQ } \\
\text { WR }\end{array}$ & $\begin{array}{l}302.2 \\
299.0\end{array}$ & $\begin{array}{r}110.9 \\
94.4\end{array}$ & $-3.2(-1.1)$ & -31.5 to 25.1 \\
\hline Fat (g) & $\begin{array}{c}\text { QFFQ } \\
\text { WR }\end{array}$ & $\begin{array}{l}69.8 \\
73.0\end{array}$ & $\begin{array}{l}29.0 \\
25.8\end{array}$ & $3.2(4.5)$ & -4.7 to 11.1 \\
\hline Fibre (g) & $\begin{array}{c}\text { QFFQ } \\
\text { WR }\end{array}$ & $\begin{array}{l}19.3 \\
20.4\end{array}$ & $\begin{array}{l}8.1 \\
7.8\end{array}$ & $1.1(5.5)$ & -1.0 to 3.2 \\
\hline Calcium (mg) & $\begin{array}{c}\text { QFFQ } \\
\text { WR }\end{array}$ & $\begin{array}{l}485.6 \\
537.5\end{array}$ & $\begin{array}{l}227.8 \\
238.1\end{array}$ & $51.9(10.1)$ & -14.6 to 118 \\
\hline Iron (mg) & $\begin{array}{c}\text { QFFQ } \\
\text { WR }\end{array}$ & $\begin{array}{r}9.7 \\
10.2\end{array}$ & $\begin{array}{l}3.6 \\
3.7\end{array}$ & $0.5(5.0)$ & -0.6 to 1.6 \\
\hline Vitamin A (RE) & $\begin{array}{c}\text { QFFQ } \\
\text { WR }\end{array}$ & $\begin{array}{c}924.7 \\
1058\end{array}$ & $\begin{array}{c}711.3 \\
1543\end{array}$ & $133(13.4)$ & -191 to 457 \\
\hline Vitamin C (mg) & $\begin{array}{l}\text { QFFQ } \\
\text { WR }\end{array}$ & $\begin{array}{l}81.7 \\
69.2\end{array}$ & $\begin{array}{l}87.4 \\
58.9\end{array}$ & $-12.5(-16.6)$ & -31.9 to 6.9 \\
\hline Alcohol (g) & $\begin{array}{l}\text { QFFQ } \\
\text { WR }\end{array}$ & $\begin{array}{l}1.3 \\
2.7\end{array}$ & $\begin{array}{l}3.7 \\
6.1\end{array}$ & $1.4(70)$ & 0.1 to 2.7 \\
\hline
\end{tabular}

${ }^{*}$ Difference $=$ mean intake $(7-$ day WR $)-$ mean intake $(Q F F Q) ; \%$ mean difference $=($ mean intake $(7-$ day WR $)-$ mean intake $(Q F F Q)) /($ mean intake (7-day WR) + mean intake (QFFQ) $) / 2 * 100$.

QFFQ and weighed records are presented in Table 2. The only significant differences were for protein $(95 \% \mathrm{CI}$ 3.2-16.4) and alcohol (95\%CI 0.1-2.7). The QFFQ seemed to underestimate intakes slightly for most nutrients, except for carbohydrate and vitamin C.

The Bland-Altman method ${ }^{6}$ was used to describe the level of agreement and the presence of proportional bias between the reported nutrient intakes from the QFFQ and the mean of the intakes from the weighed records. None of the plots showed proportional bias, as indicated by a significant Spearman rank correlation coefficient. For all nutrients, more than $90 \%$ of the respondents fell within the limits of agreement. However, the limits of agreement tended to be wide (data not shown). Figures 1 and 2 show the Bland-Altman plots for energy and vitamin A, respectively.

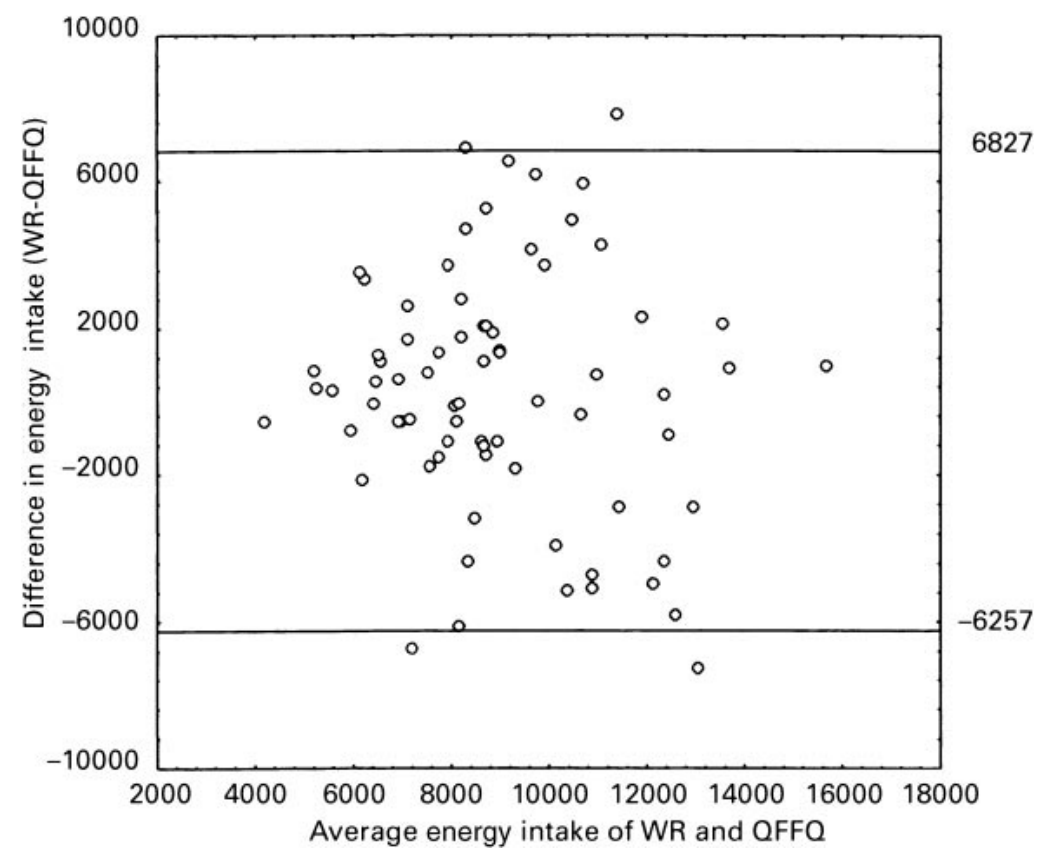

Fig. 1 Bland-Altman plot comparing the mean and difference of energy intakes from the 7-day weighed food record (WR) and quantitative food frequency questionnaire (QFFQ) $(n=74)$ 


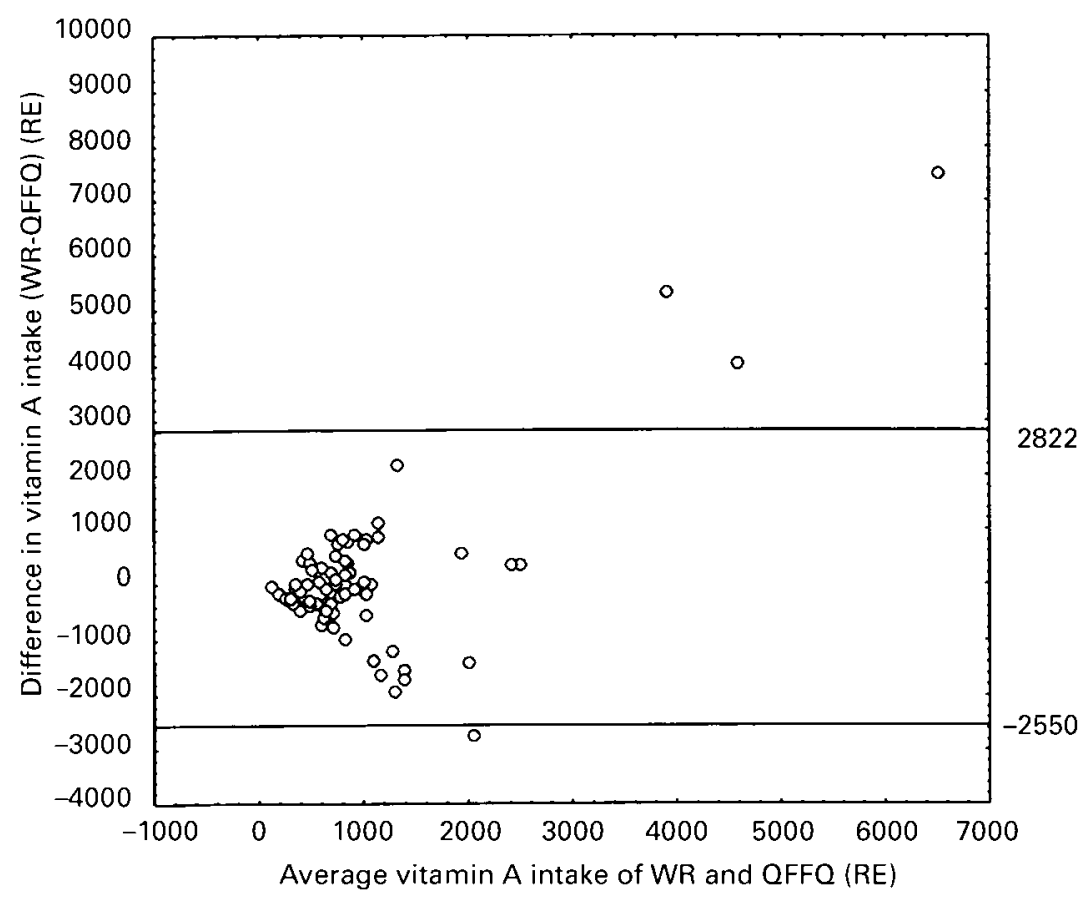

Fig. 2 Bland-Altman plot comparing the mean and difference of vitamin A intakes from the 7-day weighed food record (WR) and quantitative food frequency questionnaire (QFFQ) $(n=74)$

For energy, there was a spread of intakes from low ( $4000 \mathrm{~kJ} ; 952 \mathrm{kcal})$ to high $(15500 \mathrm{~kJ} ; 3690 \mathrm{kcal})$, with most points being between $6000 \mathrm{~kJ}(1429 \mathrm{kcal})$ and $12000 \mathrm{~kJ}$ ( $2857 \mathrm{kcal})$. Differences tended to be larger as mean intakes increased. The Spearman rank correlation coefficient $(-0.06)$ between the mean and the differences of intakes, however, was not significant (95\%CI -0.29 to 0.17). The plot for vitamin A showed that the majority of reported intakes on both the QFFQ and the weighed record were low (less than $1000 \mathrm{RE}$ ). Several high intakes showed large differences, with both the QFFQ and the weighed record overestimating intakes.

Table 3 presents the cumulative frequency of the quintile distributions for the two methods. The highest number of respondents classified into the same quintile for

Table 3 Classification of subjects into the same and adjacent quintiles* $^{*}$ of the distribution for the QFFQ and the 7-day weighed food record for an adult African sample $(n=74)$

\begin{tabular}{lcccr}
\hline & \multicolumn{4}{c}{ Cumulative \% } \\
\cline { 2 - 5 } Variable & $\mathrm{S}$ & \pm 1 & \pm 2 & \pm 3 \\
\hline Energy & 32 & 69 & 93 & 100 \\
Protein & 31 & 78 & 93 & 98 \\
Carbohydrate & 34 & 77 & 93 & 100 \\
Fat & 36 & 74 & 96 & 100 \\
Fibre & 30 & 74 & 96 & 100 \\
Calcium & 43 & 88 & 98 & 100 \\
Iron & 28 & 73 & 95 & 99 \\
Vitamin A & 57 & 85 & 93 & 98 \\
Vitamin C & 66 & 95 & 95 & 96 \\
Alcohol & 79 & 91 & 96 & 99
\end{tabular}

* $S$, classified into the same quintile; \pm 1 , adjacent quintiles; \pm 2 , two quintiles difference; \pm 3 , three quintiles difference. both distributions was for alcohol (79\%). Energy showed the poorest agreement with only $32 \%$ of respondents being classified into the same quintile and 37\% into adjacent quintiles. Less than $40 \%$ of respondents were classified into the same quintile for protein, carbohydrate, fat, fibre and iron. When adjacent quintiles were included, more than $70 \%$ of respondents were in similar quintiles for both distributions (except for energy).

Spearman rank correlation coefficients for food groups are given in Table 4. Those food groups which made substantial contributions to the diet (maize meal, bread and sugar) showed significant correlation coefficients. The correlation coefficients calculated for the nutrients and for the food groups confirmed each other. For example, the correlation coefficients for both vitamin $\mathrm{C}$ and fruit and vegetables, carbohydrate and the carbohydrate-rich food groups (fruit, maize meal, bread and sugar) and protein and the meat group were significant.

The results of the paired $t$-test for food group intakes

Table 4 Spearman rank correlations $(R)$ for food groups between the quantitative food frequency questionnaire and the 7-day weighed record in an adult African sample $(n=74)$

\begin{tabular}{llr}
\hline Food group & $R$ & \multicolumn{1}{c}{$95 \% \mathrm{Cl}$} \\
\hline Milk & 0.14 & -0.09 to 0.36 \\
Meat & 0.35 & 0.13 to 0.54 \\
Fruit & 0.38 & 0.17 to 0.56 \\
Vegetable & 0.41 & 0.20 to 0.58 \\
Maize meal & 0.56 & 0.39 to 0.70 \\
Bread & 0.25 & 0.02 to 0.45 \\
Fat & 0.21 & -0.02 to 0.42 \\
Sugar & 0.56 & 0.39 to 0.70 \\
\hline
\end{tabular}


Table 5 Mean, standard deviation and differences for food groups between the quantitative food frequency questionnaire (QFFQ) and 7-day weighed food record (WR) in an adult African sample $(n=74)$

\begin{tabular}{lccccc}
\hline Food group & Method & Mean & SD & $\begin{array}{c}\text { Difference } \\
(\%)^{*}\end{array}$ & 95\%Cl \\
\hline Milk (g) & QFFQ & 169.5 & 127.4 & $24.9(13.7)$ & -67.6 to 17.8 \\
Meat (g) & WR & 194.3 & 157.8 & & \\
& QFFQ & 124.0 & 72.8 & $14.9(11.3)$ & -34.5 to 4.7 \\
Fruit (g) & WR & 138.9 & 68.8 & & \\
& QFFQ & 198.2 & 169.1 & $-59.8(-35.5)$ & -95.9 to -24 \\
Vegetable (g) & WR & 138.4 & 117.3 & & -19.7 to 7.1 \\
& QFFQ & 97.0 & 53.2 & $-6.3(-6.7)$ & -33 to 6.8 \\
Maize meal (g) & WR & 90.7 & 61.8 & & \\
& QFFQ & 85.8 & 80.7 & $-13.1(-16.6)$ & \\
Bread (g) & WR & 72.7 & 65.0 & & \\
& QFFQ & 107.0 & 80.2 & $57.5(42.4)$ & \\
Sugar (g) & WR & 164.5 & 105.4 & & \\
& QFFQ & 26.6 & 26.4 & $-8.8(-39.6)$ & -26.5 to -8.9 \\
& WR & 17.9 & 15.7 & & \\
\hline
\end{tabular}

* Difference $=$ mean intake $(7$-day WR $)-$ mean intake $(Q F F Q) ; \%$ mean difference $=($ mean intake $(7-$ day $W R)-$ mean intake $(\mathrm{QFFQ})) /($ mean intake (7-day WR) + mean intake (QFFQ)) $/ 2 * 100$.

between the means of the QFFQ and the 7-day weighed food records are given in Table 5. Several food groups showed similar results to their main nutrient constituent. The intakes of both the milk group and calcium appeared to be underestimated by the QFFQ, as were the meat group and protein. For the carbohydrate-rich food groups, the bread group was underestimated by the QFFQ while the fruit, maize meal and sugar groups were overestimated.

The Bland-Altman plots for maize meal and sugar are shown in Figs 3 and 4, respectively, to illustrate contrasting patterns of agreement and proportional bias. There appeared to be little proportional bias for maize meal $(r=$ $0.07 ; 95 \%$ CI -0.17 to 0.29 ) although only $91 \%$ of the points fell within the limits of agreement. The plot for sugar, however, showed slightly better agreement (95\%) but significant proportional bias $(R=-0.32 ; 95 \% \mathrm{CI}-0.51$ to $-0.1)$.

\section{Twenty-four-bour urinary nitrogen}

Of the 104 24-hour urine samples collected, 16 (15\%) were excluded because no PABA was found on analysis. Thus, the sample comprised 88 urine collections of which $32(36.4 \%)$ contained $85 \%(204 \mathrm{mg})$ or more of the

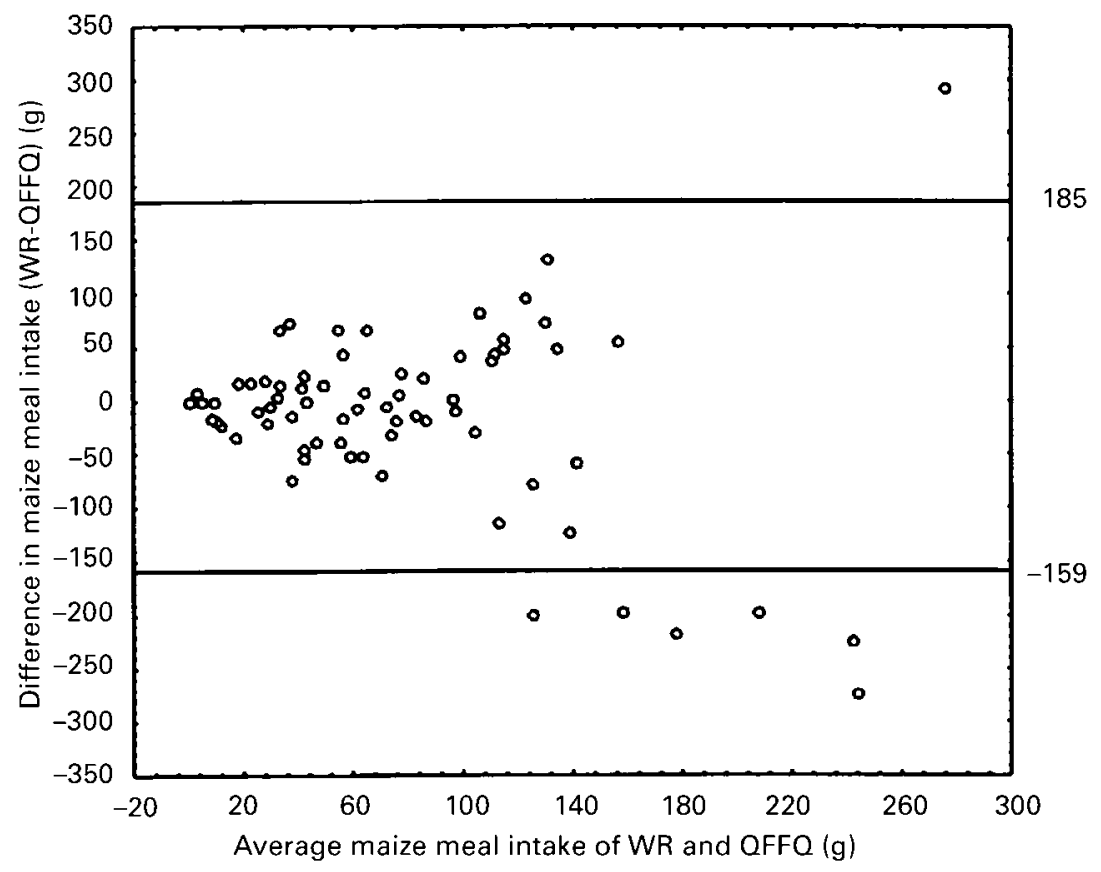

Fig. 3 Bland-Altman plot comparing the mean and difference of intakes of maize meal from the 7-day weighed food record (WR) and quantitative food frequency questionnaire (QFFQ) $(n=74)$ 


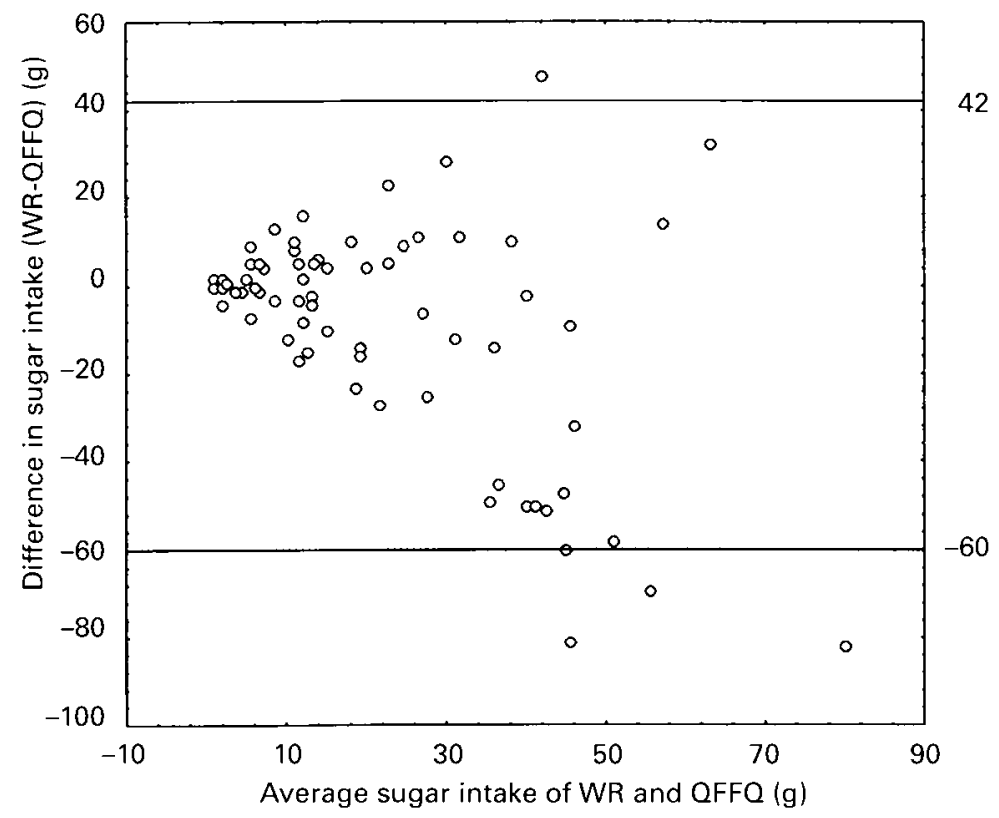

Fig. 4 Bland-Altman plot comparing the mean and difference of sugar intakes from the 7-day weighed food record (WR) and quantitative food frequency questionnaire (QFFQ) $(n=74)$

administered PABA. There was no significant correlation between the protein intake estimated from the urinary nitrogen and the reported intake from the QFFQ for either the entire sample $(R=-0.07 ; 95 \% \mathrm{CI}-0.28$ to 0.14$)$ or for the complete specimens only $(R=0.01 ; 95 \% \mathrm{CI}-0.34$ to 0.36). For the complete collections, the mean calculated urinary protein $(70.0 \pm 28.2 \mathrm{~g})$ was lower, but not significantly, than the mean reported protein intake $(80.0 \pm$ $27.0 \mathrm{~g})(95 \% \mathrm{CI}-21.8$ to 5.8$)$.

\section{Identification of underreporters}

Underreporters were identified by a ratio of EI : BMR of less than 1.2 or a UN : NI of greater than one ${ }^{4}$. Although the UN : NI was calculated for the 88 respondents who made 24-hour urine collections, the poor correlation of urinary and dietary protein made these results unreliable. Thus, only the EI : BMR ratios calculated for the QFFQ and the weighed food records of the 74 respondents who kept food diaries are presented. The mean EI : BMR obtained for the QFFQ $(1.42 \pm 0.43)$, was slightly, but not significantly, lower than that obtained for the weighed food records $(1.47 \pm 0.43)$ ( $95 \% \mathrm{CI}-0.18$ to 0.08$)$. Although the percentage of underreporters $(\mathrm{EI}: \mathrm{BMR}<1.2)$ identified for the QFFQ (43\%) was higher than the percentage identified for the weighed food records (28\%), the difference was not statistically significant (95\%CI -0.004 to 0.30$)$.

\section{Discussion}

\section{Agreement between nutrients}

The range of Spearman rank correlation coefficients (0.14-0.59) obtained in the present study was similar to ranges reported by several research groups ${ }^{10,11}$, but lower than those reported by others ${ }^{12,13}$. For specific nutrients, there were both similarities and differences to correlation coefficients reported by other studies. For example, the correlation coefficient obtained for alcohol (0.53) was the highest correlation among the macronutrients tested, a finding which has been reported by several other authors $^{13-16}$. Likewise the correlation coefficient for vitamin $\mathrm{C}(0.59)$ compared well with a reported range of $0.5-0.6^{14,15,17}$. The correlation coefficient for vitamin A was weak (0.22), but it is interesting that vitamin A often has one of the weakest correlations in a given study ${ }^{15,17}$. For iron, although the correlation coefficient in the present study was not significant (0.2), other researchers such as Larkin et al $^{18}$ have also reported poor correlations (0.09).

Our correlation coefficient of 0.24 for calcium was lower than the range of $0.4-0.7$ obtained by a number of researchers, including Thompson and Margetts ${ }^{14}$ and Bingham et $a l .{ }^{15}$ (for their Oxford questionnaire). Nevertheless, it is similar to the results obtained by Männistö et al. ${ }^{10}$ and Bingham and co-workers ${ }^{15}$ for their Cambridge questionnaire.

From the literature there appears to be no agreed point above which the test instrument can be said to be relatively valid. A number of authors have suggested that correlation coefficients in the range of $0.3-0.7$ could indicate satisfactory agreement between dietary records and food frequency methods ${ }^{3,19-21}$. Romieu and colleagues ${ }^{22}$ took correlation coefficients in the range of $0.2-0.5$ obtained in a transitional population to be satisfactory. On the basis of statistically significant correlations, the QFFQ appeared to give satisfactory agreement for all the nutrients tested 
except for iron and vitamin A. Using similar limits to other studies, the QFFQ appears to provide satisfactory agreement for energy, protein, carbohydrate, vitamin $\mathrm{C}$ and alcohol.

On the group level, in the present study, with the exceptions of carbohydrate and vitamin $\mathrm{C}$, the weighed record yielded higher mean intakes than the QFFQ. This is in agreement with the results of Männistö et $a l .{ }^{10}$, Thompson and Margetts ${ }^{14}$ and Bingham et al. ${ }^{15}$ who obtained higher mean intakes on weighed records for some nutrients but higher intakes on the food frequency questionnaire for others.

In a similar finding to those of Larkin ${ }^{18}$ and Hankin ${ }^{20}$ and their colleagues, the percentage differences between intakes derived from the weighed records and the QFFQ were larger for vitamins than for energy and macronutrients (with the exception of protein). Hankin et al. ${ }^{20}$ ascribed the large differences in vitamin intakes to the frequent recall of seasonal fruits in the diet history which were not consumed during the record period. This explanation could also apply to the present study. Oranges (the main source of dietary vitamin $\mathrm{C}$ and a seasonal fruit) were frequently reported on the QFFQ, but not on the weighed records.

The Bland-Altman plot technique is a fairly recent method for analysing validation data and hence there are few studies with which to compare our results. The usefulness of the Bland-Altman technique is to show the presence of proportional bias in a sample ${ }^{14}$. Although the limits of agreement were wide for all nutrients tested, none of the Spearman rank correlation coefficients were significant, possibly indicating that the differences in intakes were consistent over the range of intakes (data not shown). Thompson and Margetts ${ }^{14}$, using BlandAltman plots, showed that, for their male respondents, at low energy intakes the food frequency questionnaire gave lower estimates for energy, but at higher intakes it gave higher estimates than the dietary record. In the present study, the largest differences for energy were in the midrange of intakes (Fig. 1). The plot for vitamin A (Fig. 2) illustrates a different effect and could explain the low correlation coefficient. The majority of intakes were low and the differences between measurement instruments were relatively small. As the level of intake increased, so did the magnitude of difference in both directions. At exceptionally high intakes (greater than $4000 \mathrm{RE}$ ), the intakes obtained from the dietary records were remarkably higher than the QFFQ.

The percentages of respondents classified into the same or adjacent quintiles exceeded the proportion of respondents who would be classified into the same or adjacent quintiles by chance alone $(20 \% \text { and } 52 \%)^{23}$. For energy, the percentages of respondents classified into the same quintile (32\%) and adjacent quintiles (69\%) are similar to those found by O'Donnell and co-workers ${ }^{24}$. For nutrients, percentages of respondents classified into the same quintile were within a similar range to those reported in the literature, from $25 \%$ for protein ${ }^{23}$ to $68 \%$ for vitamin $C^{25}$ while reported classifications within adjacent quintiles varied from $61 \%$ for carbohydrate to $93 \%$ for alcohol ${ }^{10}$.

\section{Agreement between food groups}

The Spearman rank correlation coefficients observed for the food groups appeared lower than those observed for the nutrients. The lower range of correlation coefficients for food groups can be explained by the higher variation in intakes among foods than among nutrients. If a given food is not consumed during the record period, its intake will be zero. Nutrient intakes, however, may vary but a zero intake is unlikely. The range of correlation coefficients obtained in the present study is similar to some reported ranges ${ }^{26}$ but lower than others ${ }^{10}$. Similarly to the results of Salvini et ll $^{26}$, correlation coefficients for frequently consumed foods were higher than for other foods. In our study, the highest correlation coefficient was obtained for maize meal, which is the staple food of the population. Vegetables and fruits were not consumed in large amounts in the study population. Nevertheless, the correlation coefficients for these foods were among the highest. Possibly, the small amounts and limited variety consumed made recall and recording easier.

From the results of the food group analysis it appears that the agreement between food intakes obtained from the QFFQ and the 7-day weighed record was lower than that obtained for nutrients. Since intakes of food groups may be highly variable within individuals, longer recording periods may be necessary to account for within person variability and thus to reflect the usual intake ${ }^{27}$.

\section{Validation by biomarkers}

The high percentage of incomplete 24-hour urine collections (64\%) meant that urinary nitrogen could not be used as a validator of dietary protein. The poor response might be ascribed to respondents not taking the full dose of PABA, taking the tablets at the wrong times or to environmental and methodological factors affecting the PABA content. Although these factors might have played a role in some cases, the mean volume and the nitrogen content of the incomplete specimens were lower than the complete specimens. Several reasons could have contributed to respondents not collecting complete samples. First, respondents may not have fully understood the instructions or the importance of collecting for the full 24 hours. Second, the circumstances under which many of the respondents had to collect urine were difficult, even if they fully intended to comply. For example, in some areas, outside toilets are shared by a number of families, making privacy difficult. There may not have been a suitable place to store the bottles and respondents might have had to explain what they were doing not only to their families but to curious outsiders as well. Additional difficulties might have been experienced by volunteers at their 
place of work in storing the collections and carrying them home.

Another reason for the poor results is that one 24-hour urine collection cannot be expected to reflect habitual dietary protein intake as do the QFFQ and the 7-day weighed records. As pointed out by Bingham ${ }^{4}$, intraindividual variation in urinary nitrogen excretion is high. Thus, on a daily basis, urinary nitrogen correlates poorly with dietary nitrogen. Although satisfactory results have been obtained with 3 or 4 days of urine collections $^{20,28}$, to estimate nitrogen excretion within $5 \%$ standard error, 8 days of collections are needed ${ }^{4}$. In our study, the logistics of tracing respondents, providing the equipment, making the collections and transporting the specimens over long distances would have made this extremely difficult, especially in the rural and farm areas.

The ratio of EI : BMR provides an objective assessment of whether reported energy intakes are reasonable in terms of energy requirements ${ }^{4}$. The ratio below which energy intakes have been taken as invalid has differed among studies, but most researchers ${ }^{29,30}$ have set the cut-off ratio between 1.1 and 1.54. In the present study, the ratio of 1.2 suggested by Bingham ${ }^{4}$ was taken as the lowest reasonable EI: BMR ratio. Higher EI : BMR ratios were obtained for the 7-day weighed records than for the QFFQ, suggesting a greater tendency to underreporting on the QFFQ. The ratios obtained in the present study are comparable to several other studies which used weighed records ${ }^{29,30}$ and higher than others ${ }^{31}$. The percentage of underreporters for the weighed records is within the range reported by several other researchers ${ }^{29,31}$. On the other hand, the percentage of underreporters identified for the QFFQ is somewhat higher than the percentages obtained for semiquantitative food frequency questionnaires ${ }^{32}$. It seems that, for these respondents, the weighed record was a more accurate measure of energy intake than the QFFQ.

Several authors have questioned the use of the Schofield equations ${ }^{9}$ for the estimation of $\mathrm{BMR}^{30,31,33,34}$. In a recent study on 14 elderly respondents in Cape Town, the mean predicted BMR from the Schofield equations was $7 \%$ and 14\% higher than BMR measured using the heart rate monitoring technique for males and females, respectively $^{35}$. If these findings are applied to the present study, the true BMR of the respondents may have been lower, and thus the EI : BMR ratios may have been closer to the limits set for minimal activity ${ }^{36}$. As a result the percentage of possible underreporters could have been lower. Unfortunately, as there are no known studies which have measured BMR in African populations similar to those of the North West Province, this speculation cannot be verified.

From the results obtained in the present study, it is clear that relative validity of a QFFQ cannot be thought of as a single entity which applies to the whole QFFQ. The relative validity varied among nutrients and according to the aspect of the QFFQ being tested. In terms of the ability of the QFFQ to rank respondents within the distribution similarly to the reference method, the QFFQ performed satisfactorily for carbohydrate, fat, calcium, vitamin A, vitamin $\mathrm{C}$ and alcohol. Energy, protein, fibre and iron met the criteria for validity on only one test. Therefore, although the QFFQ might be able to classify respondents relatively accurately within the distribution, the results obtained in the dietary intake study need to be interpreted with caution. On the level of group agreement between the QFFQ and the 7-day weighed record, the QFFQ significantly underestimated mean protein and alcohol intakes. Energy, fat, fibre, calcium, iron and vitamin A were slightly underestimated by the QFFQ. As demonstrated by the Bland-Altman plots, there was a tendency for the differences in intakes obtained by the two methods to increase as the intake increased, suggesting better agreement at low intake levels.

As only energy and nine nutrients were tested for relative validity, it cannot be assumed that the measurement of all nutrients by the QFFQ would yield similarly valid results. However, the nutrients selected are those which are most representative of the total dietary intake and thus the results could be applied to the dietary intake as a whole. Although agreement between the QFFQ and the 7-day weighed records was poorer for food groups than for nutrients, the QFFQ appeared to be able to measure the intake of staple and frequently consumed foods satisfactorily.

The results of the present study highlight the need for more than one method to test the relative validity of a QFFQ, as pointed out by several authors ${ }^{3,4}$. Considering the difficulties experienced in the collection of 24-hour urine specimens and the poor results obtained, estimated BMR appeared to be the more practical biomarker in the African population of North West Province. Practical and cost-effective ways of collecting urine or other biomarkers must be investigated, as should the development of population-specific equations for BMR estimations. Alternatives to the weighed food record as the reference standard and, indeed, the QFFQ as a dietary assessment method in developing populations need to be explored.

In the light of the development of numerous techniques for validation data analysis, there is a need to standardize techniques and values which identify relative validity. The need for international standardization in the methodology and reporting of validation studies has been emphasized in editorials in the European Journal of Clinical Nutrition ${ }^{37}$ and the British Journal of Nutrition ${ }^{38}$. Collaboration between established research centres and groups working in developing countries could contribute to the improvement of the quality of dietary research in these areas and give established centres an understanding of the practical difficulties involved in conducting dietary intake research in areas lacking the infrastructure and technologies of first world countries. 


\section{Acknowledgements}

This research was supported by a grant from the South African Foundation for Research Development. The authors wish to thank the fieldworkers for their dedicated data collection and all the respondents for their willing cooperation, often under very difficult circumstances.

\section{References}

1 Popkin BM. The nutrition transition in low income countries: an emerging crisis. Nutr. Rev. 1994; 52: 285-9.

2 Drewnowski A, Popkin BM. The nutrition transition: trends in the global diet. Nutr. Rev. 1997; 55: 31-43.

3 Willett W. Nutritional Epidemiology. Monographs in Epidemiology and Biostatistics No. 15. Oxford: Oxford University Press, 1990

4 Bingham SA. Validation of dietary assessment through biomarkers. In: Kok FJ, van't Veer P, eds. Biomarkers of Dietary Exposure. Proceedings of the 3rd Meeting on Nutritional Epidemiology. London: Smith-Gordon, 1991: $41-52$.

5 Grant KI, Langenhoven ML, Stockton MA, Day RS, Bauermeister P. FoodFinder dietary analysis software. Release 1.10. Parowvallei: Medical Research Council, 1992.

6 Bland JM, Altman DG. Statistical methods for assessing agreement between two methods of clinical measurement. Lancet 1986; i: 307-11.

7 Bingham S, Cummings JH. The use of 4-aminobenzoic acid as a marker to validate the completeness of $24 \mathrm{~h}$ urine collections in man. Clin. Sci. 1983; 64: 629-35.

8 Maroni BJ, Steinman TI, Mitch WE. A method for estimating nitrogen intake of patients with chronic renal failure. Kidney Int. 1985; 27: 58-65.

9 Schofield WN. Predicting basal metabolic rate, new standards and review of previous work. Hum. Nutr. Clin. Nutr. 1985; 39C (Suppl.): 5-41.

10 Männistö S, Virtanen M, Mikkonen T, Pietinen P. Reproducibility and validity of a food frequency questionnaire in a case-control study on breast cancer. J. Clin. Epidemiol. 1996; 49: 401-9.

11 Coates RJ, Monteilh CP. Assessment of food-frequency questionnaires in minority populations. Am. J. Clin. Nutr. 1997; 65 (Suppl.): S1108-15.

12 Lindroos A-K, Lissner L, Sjostrom L. Validity and reproducibility of a self administered dietary questionnaire in obese and non-obese subjects. Eur. J. Clin. Nutr. 1993; 47: 461-81.

13 Goldbohm RA, van den Brandt PA, Brants HAM, van't Veer PALM, Sturmans F, Hermus RJJ. Validation of a dietary questionnaire used in a large-scale prospective cohort study on diet and cancer. Eur. J. Clin. Nutr. 1994; 48: 253-65.

14 Thompson RL, Margetts BM. Comparison of a food frequency questionnaire with a 10-day weighed record in cigarette smokers. Int. J. Epidemiol. 1993; 22: 824-33.

15 Bingham SA, Gill C, Welch A, et al. Comparison of dietary assessment methods in nutritional epidemiology: weighed records $v$ 24-h recalls, food-frequency questionnaires and estimated-diet records. Br. J. Nutr. 1994; 72: 619-43.

16 Bonifacj C, Gerber M, Scali J, Daures JP. Comparison of dietary assessment methods in a southern French population: use of weighed records, estimated-diet records and a foodfrequency questionnaire. Eur. J. Clin. Nutr. 1997; 51: 217-31.

17 Rimm EB, Giovanucci EL, Stampfer MJ, Colditz GA, Litin LB, Willett WC. Reproducibility and validity of an expanded selfadministered semiquantitative food frequency questionnaire among male health professionals. Am. J. Epidemiol. 1992; 135: 1114-26.
18 Larkin FA, Metzner HL, Thompson FE, Flegal KM, Guitr KE. Comparison of estimated nutrient intakes by food frequency and dietary records in adults. J. Am. Diet. Assoc. 1989; 89 215-23.

19 Block GB, Woods M, Potosky A, Clifford C. Validation of a self-administered diet history questionnaire using multiple diet records. J. Clin. Epidemiol. 1990; 43: 1327-35.

20 Hankin JH, Wilkens LR, Kolonel LN, Yoshizawa CN Validation of a quantitative dietary history method in Hawaii. Am. J. Epidemiol. 1991; 133: 616-28.

21 Margetts BM, Cade JE, Osmond C. Comparison of a food frequency questionnaire with a diet record. Int.J. Epidemiol. 1989; 18: 868-73.

22 Romieu I, Meir J, Stampfer J, et al. Food predictors of betacarotene and alpha-tocopherol: validation of a food frequency questionnaire. Am. J. Epidemiol. 1990; 131: 864-76.

23 Kune S, Kune GA, Watson LF. Observations on the reliability and validity of the design and diet history method in the Melbourne colorectal cancer study. Nutr. Cancer 1987; 9: 520.

24 O'Donnell MG, Nelson M, Wise PH, Walker DM. A computerized questionnaire for use in diet health education. 1. Development and validation. Br. J. Nutr. 1991; 66: 3-15.

25 Willett WC, Sampson L, Stampfer MJ, et al. Reproducibility and validity of a semiquantitative food frequency questionnaire. Am. J. Epidemiol. 1985; 12: 51-65.

26 Salvini S, Hunter DJ, Sampson L, et al. Food-based validation of a dietary questionnaire: the effects of week-to-week variation in food consumption. Int. J. Epidemiol. 1989; 18: 858-67.

27 Hartman AM, Brown CC, Palmgren J, et al. Variability in nutrient and food intakes among older middle aged men. Implications for design of epidemiologic and validation studies using food recording. Am. J. Epidemiol. 1990; 132: 999-1012.

28 Black AE, Jebb SA, Bingham SA, Runswick SA, Poppitt SD. The validation of energy and protein intakes by doubly labelled water and 24-hour urinary nitrogen excretion in post-obese subjects. J. Hum. Nutr. Diet. 1995; 8: 51-64.

29 Bingham SA, Cassidy A, Cole TJ, et al. Validation of weighed records and other methods of dietary assessment using the $24 \mathrm{~h}$ urine nitrogen technique and other biological markers. Br. J. Nutr. 1995; 73: 531-50.

30 Price GM, Paul AA, Cole TJ, Wadsworth EJ. Characteristics of the low-energy reporters in a longitudinal national dietary survey. Br.J. Nutr. 1997; 77: 833-51.

31 Cole TJ, Black AE, Coward WA, Prentice AM. Total energy expenditure and basal metabolic rate. Am. J. Clin. Nutr. 1996; 63: 281-2

32 Wheeler C, Rutishauser L, Conn J, O’Dea K. Reproducibility of a meal-based food frequency questionnaire. The influence of format and time interval between questionnaires. Eur. J. Clin. Nutr. 1994; 48: 795-809.

33 Hayter JE, Henry CJK. A re-examination of basal metabolic rate predictive equations: the importance of geographic origin of subjects in sample selection. Eur. J. Clin. Nutr. 1994; 48: 702-7.

34 Shetty PS, Henry CJK, Black AE, Prentice AM. Energy requirements of adults: an update on basal metabolic rates (BMRs) and physical activity levels (PALs). Eur.J. Clin. Nutr. 1996; 50 (Suppl.): S11-23.

35 Charlton K, Wolmarans P, Kruger M, Labadarios DL, Aronson I, Lombard CJ. Micronutrient status of older South Africans. S. Afr. Med.J. 1998; 88: 653-8.

36 Goldberg GR, Black AE, Jebb SA, et al. Critical evaluation of energy intake data using fundamental principles of energy physiology: I. Derivation of cut-off limits to identify underrecording. Eur. J. Clin. Nutr. 1991; 45: 569-81.

37 Garrow JS. Validation of methods for estimating habitual diet: proposed guidelines. Eur. J. Clin. Nutr. 1995; 49: 231-2.

38 Southgate DAT. On the quality of nutritional data. Br.J. Nutr. 1995; 73: 335-6. 